\title{
Over the Suppressor from Phytophthora infestans Single Molecule Signaling in Hypersensitive Cell Death of Host Cell against $\mathrm{Ca}^{2+}$-Dependent Protein Kinases
}

\section{Naotaka Furuichi*}

Department of Molecular Plant Pathology, Niigata University School of Science and Technology, Niigata, Japan

*Corresponding author: Naotaka Furuichi, Ph.D, Lab of Molecular Plant Pathology, Niigata University, School of Science and Technology, Igarashi 2-8050, 950-2181, Japan, Tel: 81-25-262-7520; Fax: 81-25-262-6854; E-mail: nfuru@agr.niigata-u.ac.jp

Rec date: July 08, 2015; Acc date: July 10, 2015; Pub date: July 12, 2015

Copyright: @ 2015 Furuichi N. This is an open-access article distributed under the terms of the Creative Commons Attribution License, which permits unrestricted use, distribution, and reproduction in any medium, provided the original author and source are credited.

\section{Editorial}

The interaction between plants and a suppressor or a host-selective toxin (HST) producing pathogen leads often to suppression of rapid and localized cell death in the context of a hypersensitive response [1]. The suppressor for hypersensitive response (HR) was reported from Phytophthora infestans [1]. The elicitor of hyphal wall of $P$. infestans was also reported from Tomiyama group [2]. Recently, we have reported the isolation of PiPE effector gene from P. infestans, of which peptide induce the generation of active oxygen species (AOS) and HR cell death in potato and tomato [3]. In these reported physiological events for the induction of HR and AOS generation, and the inhibition of these resistance responses, $\mathrm{Ca}^{2+}$-dependent protein kinase (CDPK) was involved in for the signal cascades in host cell[4,5]. It was suggested that CDPK molecule is a switch for the induction or the inhibition of HR response in host cell $(2008)[4,6]$.

The mechanisms of these molecular infection events are presumed to be as follows: (1) initial recognition of the PAMPS (pathogen associated molecular patterns) and the suppressor of the pathogen by host plasma membrane in the infection process [2,7-10]; (2) increase in $\mathrm{Ca}^{2+}$ influx and the kinase activation in the cells [11,12]; and (3) induction of biochemical defense in the host cells [5]. A PAMP of Phytophthora infestans and the hyphal wall components (HWC) elicited HR. In our attempt to explore the HR suppressor and the antigenic potential of $P$. infestans derived surface structure to elicit non-specific defense response in potato, we have previously identified PiPE, an elicitor peptide for HR and the generation of AOS [3]. The PiPE was shown to serve as a recognition PAMP for the activation of HR.

However, from the reported RXLR-genes of Phytophthora species, what is the real product is not yet known. Receptor binding of PiPE evokes a PAMP-specific cytoplasmic streaming, and the brownian movement and gelation in the cytosol, production of AOS as well as translational activation of CDPK kinases, all of which are important elements for the transmission of the PiPE signal. From these evidences, we proposed that PiPE and a HST (host-selective-toxin) from Alternaria solani, can regulate HR by the binding with CDPK on the plasma membrane of potato as reported $[4,5]$.

So far, the RXLR genes from Phytophthora spp. interacted with the resistance genes in gene-for-gene level in the host cell [13]. However, how did a secreted protein from Avr4/6 with an RXLR-dEER protein translocation motif work with the receptors in host cells, is not yet resolved.

In the future works, we need the single molecule detection and observation in situ in host cells. For the new frontier of plant infection mechanisms of the host-pathogens interaction, we will explain the infection process by using the single molecule interaction in situ analysis in host cell with regard to the effector-receptor interaction and the signal transduction in a specific host-parasite interaction for the explanation of hypersensitive response in host cells (Specific Issue, 2015, J Plant Pathology and Microbiology, in preparation).

\section{References}

1. Doke N, Tomiyama K, Furuichi N (1982) Elicitation and supression of hypersensitive response in host-parasite specificity, In: Asada Y et al. (eds) Plant Infection: The physiological and Biochemical Basis. Japan Sci. Soc. Press, Tokyo/Springer-Verlag, Berlin. pp. 79-96.

2. Furuichi N (1998) Identification of receptor site of the suppressor isolated from Phytohthora infestans in potato plasma membrane by using surface plasmonl biosensor. Molecular Genetics of Host-Specific Toxins in Plant Disease. Netherlands: K.Kohmoto and O.C. Yoder (eds).

3. Furuichi N (2013) A novel elicitor (PiPE) from Phytophthora infestans induces active oxygen species and the hypersensitive response in potato. Global Journal of Medical Research 8: 1-14.

4. Furuichi N, Yokokawa K, Ichihara T (2008) Ca2+-dependent protein kinase in tomato is stimulated by host-selective toxin from Alternaria solani. Plant Stress 2: 152-155.

5. Furuichi N, Yokokawa V (2008) PiP elicitor and suppresso from Phytophthora infestans regulates Ca2+-dependent protein kinase (CDPK) in the plasma membrane of potato. Japanese Journal of Plant Sciences 2: 35-38.

6. Furuichi N (2014) PiPE, a Phytophthora-associated PAMPS from P.infestans, binds to a Ca2+-dependent protein kinase (CDPK) in potato for the induction of hypersensitive reaction. Clinical and Experimental Pathology 4: 156.

7. Furuichi N, Tomiyama K, Doke N (1980) The role of potato lectin in the binding of germ tubes of Phytophthora infestans to potato cell membrane. Physiological Plant Pathology 16: 249-256.

8. Langsdorf G (1990) Investigations on Alternaria solani infections: Detection of alternaric acid and a susceptibility-inducing factor in the spore-germination fluid of A. solani. J Phytopathology 128: 271-282.

9. Furuichi N (1997) Analysis of the receptor protein of the suppressor from Phytophthora infestans: toward gene cloning of the receptor Protein Kinase. In: 7th Annual Meeting of Plant-Microbe Interaction Obihiro Chikusan University.

10. Furuichi N (1993) Elicitor and suppressor of Phytophthora infestans stimulate phosphorylation of plasma membrane proteins from potato and bean tissues. in International Symposium on Host-Specific Toxin: Biosynthesis, Receptor and Molecular Biology. Tottori, Japan.

11. Furuichi N, Kanayama T, Inagawa J (1995) Analysis of a receptor site of the suppressor isolated from Phytophthora infestans in potato plasma membrane. in 5th Annual Meeting of Plant-Microbe Interaction. Kagoshima university JSPMI.

12. Furuichi N, Suzuki J (1988) Monoclonal antibodies to soluble glucan, suppressor of hypersensitivity of Phytophthora infestans. in 5th International Congress of Plant Pathology. Kyoto, Japan. 
Citation: Furuichi N (2015) Over the Suppressor from Phytophthora infestans Single Molecule Signaling in Hypersensitive Cell Death of Host Cell against $\mathrm{Ca}^{2+}$-Dependent Protein Kinases. J Plant Pathol Microb 6: e109. doi:10.4172/2157-7471.1000e109

Page 2 of 2

13. Dou D, Kale SD, Liu T, Tang Q, Wang X, et al. (2010) Different domains of Phytophthora sojae effector Avr4/6 are recognized by soybean resistance genes Rps4 and Rps6. Mol Plant Microbe Interact 23: 425-435. 